\title{
Fear levels of the childbirth of primiparaous women applying to emergency
}

\section{obstetric unit}

\author{
Havva Apaydın, Kamile Kukulu
}

Akdeniz University, Nursing Faculty, Antalya, Turkey

\section{RESEARCH}

Please cite this paper as: Apaydın H, Kukulu K. Fear levels of the childbirth of primiparaous women applying to emergency obstetric unit. AMJ 2019;12(1):1-10. https://doi.org/10.21767/AMJ.2018.3484

\section{Corresponding Author:}

Kamile Kukulu

Akdeniz University, Nursing Faculty, Campus, Antalya, Turkey

Email: kkamile@akdeniz.edu.tr

\section{ABSTRACT}

\section{Background}

Emergency service is a complex and dynamic environment mostly simultaneously managing the conditions of different patients and which is delicate in terms of time. Health care providers should be aware of influence the environment during labour.

\section{Aims}

The aim of this research was to determine the level of fear of childbirth of primiparaous women, who has applied to emergency obstetric units. We also examined some variable which could effect on the level of fear of childbirth such as reasons for applying the emergency obstetric units, knowledge about birth process and readiness to birth.

\section{Methods}

This study is a cross-sectional study. The sample of the study is 473 primiparaous women who have applied to emergency obstetric units. A personal information form and "Wijma Birth Expectancy / Experience Scale Version" have been used to determine the fear level of childbirth by conducting face-to-face interviews.

\section{Results}

It has been determined that 67.7 per cent of the pregnant women have applied to the emergency unit due to pain. It has also determined that the mean score of fear of childbirth is $66.33 \pm 25.25$ among women who have applied to emergency services. Also, 21.8 per cent of the women have been found to have a fear of childbirth at a severeclinical level. Women who have early membrane ruptures have the highest level of fear of childbirth. There is also significant difference between women's fear of childbirth level depending on knowledge about birth process, readiness to give birth and desired/planned birth $(p=0.000)$.

\section{Conclusion}

This study showed that on third of the primiparaous who apply to emergency obstetric care has a severe grade of fear of childbirth. It has been determined that fear of childbirth has been found to be lower in the women who has received childbirth education, who has known what they would live during birth, and who has felt ready for delivery. This finding suggests that childbirth education is important to provide low level fear of childbirth for women who apply to emergency obstetric unit.

\section{Key Words}

Emergency birth, fear of childbirth, nursing, primiparaous, tokophobia

\section{What this study adds:}

\section{What is known about this subject?}

Generally, pregnancy and delivery are mostly positive life experiences for women. Fear of childbirth is happening more in primipar women. Negative birth experiences affect subsequent pregnancies and births.

2. What new information is offered in this study? Determining the level of birth fear of women and helping them cope with this fear is an important responsibility for health personnel in emergency obstetric unit. 
3. What are the implications for research, policy, or practice?

The enlightenment of the women and the provision of readiness for childbirth are important factors in decreasing the childbirth fear

\section{Background}

Emergency units could be the ones increasing the fear and stress level for the pregnant women under a condition such as pregnancy in which the process and result cannot be seen or foreseen. The childbirth time and moment are full of mysteries even for the pregnant not having any complication history and who will not undergo any planned caesarean operation. ${ }^{1}$ It is thought that the emergency obstetric units may increase the fear and stress level in most women due to the reasons such as meeting an unknown situation in the act of pregnancy and childbirth, risk for the development of complication and birth contractions. ${ }^{2}$

Dangerous symptoms such as bleeding, hypertension, pain etc. requiring emergency obstetric operation peculiar to pregnancy may trigger the pregnant to feel a fear of childbirth. Fears peculiar to pregnancy are the physical symptoms depending on the health of the foetus and pregnancy, parent relations, relations with other people, changes in the body, pregnancies including the birth and the action of birth and the maternal fears and worries related to the health of the baby. ${ }^{3-5}$

When the literature has been examined; while there are studies in which the patients applying to emergency service have been evaluated, few studies have been observed in which the conducted on emergency obstetric units. There are no studies which examine the level of fear of childbirth of primiparaous women who apply to emergency obstetric units. Aim of this study was to determine the fear of childbirth levels and affecting factors regarding reasons for applying the emergency units, knowledge about birth process and readiness to give birth.

\section{Method}

\section{Design}

The study has been conducted as a descriptive crosssectional study. It has been conducted in the emergency unit of obstetrics and gynaecologic diseases of Antalya Training and Research Hospital, Turkey. There is a three-bed pregnant monitoring room in the emergency unit of obstetric and gynaecological diseases in which non-stress test is conducted and in which there are patient reception room, a gynaecological treatment table and an ultrasound treatment table. The health staff works between the hours 08.00-16.00 and 16.00-08.00 in the emergency unit of obstetric and gynaecological diseases. Three midwives and one assistant doctor work in the day and night working hours. The women with the complaints of childbirth, obstetric and gynaecological diseases apply to the emergency unit of obstetric and gynaecological diseases. There is not any triage system to accept women for the emergency obstetric units. All women who apply to emergency obstetric units with some complaints is accepted to evaluate whether there is any risk for women and foetus' health.

Four hundred seventy three pregnant women applying to the emergency unit of Antalya Training and Research Hospital Obstetric and Gynaecological Diseases within six months between the dates August 2015-February 2016 have been taken to the sampling. Among the women included in the study; the mothers who are nulliparous, at least at the 28th week of their pregnancy, above the age of 18 and under the age of 35 , with no chronic systemic diseases, with no abnormality in their foetus, with no psychiatric diagnosis and with single foetus have been taken to the scope of the study. However, women who have massive bleeding was excluded from study.

\section{Data collection}

Written work permit and ethical approval (Approval Number: 2015-102) have been taken from the Ethics Committee of the Hospital and from Antalya Training and Research Hospital Head Physician for the conduction of this study. In addition; explanations have been given to the pregnants to participate in the study and their verbal and written permits have also been taken.

The data have been collected from 473 primiparaous women applying to the emergency unit of the obstetric and gynaecological diseases department of the hospital, meeting the sample inclusion criteria and accepting to participate in the study. The purpose of the study has been explained to the pregnants following the conduction of their first treatment and data collection forms have been distributed. Forms have been filled by the researcher via the face-to-face interview method within 10-15 minutes.

Personal information form prepared as based on literature has been used for the purpose of determining the sociodemographic properties of the sample in the study. Personal Information Form covers the questions examining the reason of the pregnants for applying to emergency 
obstetric unit, their working status, status of desiring the pregnancy, status of taking any preparation training for childbirth and the status of readiness for childbirth. There are questions covering the socio-demographic properties of the pregnants in the personal information form. Moreover; "Wijma Childbirth Expectation/Experience Scale Version A" has been used for the purpose of determining the fear levels of the pregnants regarding the childbirth. ${ }^{6-8}$

Wijma Childbirth Expectation/Experience Scale - Version A Wijma Childbirth Expectation/Experience Scale Version $A$ (W-DEQ) has been developed for the purpose of measuring the childbirth fear experienced by the women. ${ }^{9}$ The scale consists of 33 items. The responses in the scale are numbered from 0 to 5 and the scale is in 6-point likert scale. 0 is expressed as "completely" and 5 is expressed as "never". While the minimum point in the scale is 0 , maximum point is 165 . The childbirth fear of the women increases as the point increases. The questions no. 2, 3, 6, 7, $8,11,12,15,19,20,24,25,27$ and 31 are calculated by reversing. Cronbach alpha value of the scale adapted to Turkish and whose reliability and validity have been conducted by Körükcü et al. ${ }^{10}$ is 0.89 and Split-half reliability is 0.91 . In the evaluation of the scale; 0-37 points have been classified as low level childbirth fear, 38-65 points have been classified as medium level childbirth fear, 66-84 points have been classified as high level childbirth fear and 85-165 points have been classified as clinical level childbirth fear.

\section{Data analysis}

The attained data have been evaluated by using the convenient statistical methods in Statistical Package for the Social Sciences (SPSS) 20.0 program. Demographic variables have been summarized in the type of number and percentage. Levene test has been conducted for the purpose of determining whether the variances of the masses in which participants have been determined are equal or not. Independent two-sample test statistics have been conducted for the comparison of the scale points between two groups and one-way variance analysis has been conducted in more than two group comparisons. As a result of the variance analysis, post-hoc tests have been conducted for the purpose of revealing which group average is different from others and which group the difference stems from in the conditions in which $F$ test statistics is significant. In post-hoc tests, Scheffe test has been preferred for the purpose of testing the average of one group according to other group averages.

\section{Results}

Almost half of the women forming the sample (48.4 per cent) are between the ages 21-25. When the educational status of the women has been examined, it has been determined that 35.9 per cent of them are graduates of middle school and the majority of them (88.2 per cent) do not work in a regular job (Table 1).

When the pregnancy and childbirth-peculiar properties of the women have been examined, it has been determined that 62.6 per cent of them are in the interval of 37-40 weeks and the pregnancy of 63.4 per cent of them is desired and planned pregnancies. It has also been determined that almost all of the women (93.9 per cent) have not taken any preparation training for pregnancy and childbirth and they do not know anything about the things they will experience during the childbirth (92.0 per cent) (Table 1 ). It has been detected that 67.7 per cent of the pregnants have applied due to pain and 15.8 of them have applied due to early membrane rupture (EMR) (Table 2).

The average childbirth fear point of the women (W-DEQ-A) applying to the emergency obstetric care unit has been determined as $66.23 \pm 25.25$. It has been found that according to W-DEQ-A scale; 12.3 per cent of the pregnant applying to the emergency service experience childbirth fear in low level, 31.1 per cent of them experience childbirth fear in high level and 21.8 per cent of them experience childbirth fear in clinical level. It has also been determined in the study that only the women applying to the emergency service due to delayed pregnancies experience childbirth fear in medium level (Table 3).

It has been determined that there is no pregnant women who have low level of fear of childbirth according to reasons for applying the emergency obstetric units. The women applying to emergency service due to only delayed pregnancies experience medium level fear of childbirth when compared to the mean score of scale (Table 3 ). In Table 4; according to the Scheffe test results, it has been determined that there is a significant difference the level of fear of childbirth between the pregnant women who applied to emergency obstetric units due to delayed pregnancies and early membrane rupture.

Levene test statistics conducted for the purpose of determining whether the variances of the masses in which participants have been determined are equal or not has been attained as 0.707 and $p$ value has been attained as 0.587 . According to this result; the variances of the points given by the participants regarding the application reasons 
to emergency units are homogeneous. Because both assumptions have been provided, one way variance test has been conducted. F statistics calculated according to the test result has been attained as 3.263 and $p$ value has been attained as 0.012 (Table 3 ). In other words; there are meaningful differences between the application reasons of the women applying to emergency service and the childbirth fear. ${ }^{11}$

It has been concluded that the desired, but unplanned; and desired and planned pregnancy conditions have meaningful impacts on the childbirth fear $(t=5.673, p=0.000)$. Because the difference is 0.39 between averages of planned and unplanned pregnancy. It has been determined that the childbirth fear of those experiencing desired and planned pregnancy is less than that of desired, but unplanned pregnancy (Table 5).

It has been observed that whether the participants have sufficient information in the issue of what they will experience during the childbirth has a meaningful impact on the childbirth fear. Because the difference is 0.13 between whether the participants have sufficient information in the issue of what they will experience during the childbirth or not, it has been determined that the childbirth fear of those not knowing what they will experience during the childbirth is higher than women who have knowledge about birth process (Table 5 ).

It has been detected that whether the participants feel themselves ready for childbirth has a meaningful impact on the childbirth fear. Because the difference is -0.51 between whether the participants feel themselves ready for childbirth or not, it has been determined that the childbirth fear of those not feeling themselves ready for childbirth is higher than those feeling themselves ready (Table 5).

\section{Discussion}

In the study; the fear levels regarding the childbirth experienced by the primiparaous pregnant women applying to the emergency service and the factors affecting the fear have been examined. 62.6 per cent of the women are in the interval of 37-40 weeks of their pregnancies and the pregnancy 63.4 per cent of them is a desired and planned pregnancy. 93.9 per cent of the women have not taken any preparation training for childbirth and pregnancy (Table 1).

The average childbirth fear point average of the women applying to the emergency unit of obstetric and gynaecological diseases has been determined as $66.33 \pm 25.25$ (Table 2). It has been found that according to
W-DEQ-A scale; 12.3 per cent of the pregnants applying to the emergency service experience childbirth fear in low level, 31.1 per cent of them experience childbirth fear in high level and 21.8 per cent of them experience childbirth fear in clinical level (Table 2). In a study conducted with the Australian women who will become mothers for the first time, higher level childbirth fear level has been determined in primiparities when compared to multiparities. ${ }^{12}$ Not having any childbirth before and not knowing the normal childbirth have been related to the experience of childbirth fear in high level. ${ }^{13-16}$ Whether almost half of the women have childbirth fear at high and clinical level may stem from the fact that the study has been conducted in emergency gynaecological birth service and there is no sufficient information regarding this unit.

It has been determined that women frequently apply to the emergency service due to pain with 67.7 per cent and due to watering with 15.8 per cent (Table 3 ). In our study; when the complaints of the pregnant applying to the emergency service have been examined, it has been detected that the most frequent application complaint is stomach-ache $(20.5$ per cent). ${ }^{17}$ It could be considered that they often apply to the emergency mostly for the pain due to the anxieties regarding the health of the baby and mother and due to the fact that the real childbirth symptoms are unknown.

In this study, it has been observed that there is a significant difference between the childbirth fear and the application reasons of the women applying to the emergency service of obstetric and gynaecological diseases department (Table 2). We were thought that the reason of the admission of obstetric emergency department might be related with fear of childbirth. Therefore, we compared the reason of admission of obstetrics emergency department and level of fear of childbirth. It is known that birth is coming after opening the amniotic pouch, but women are women are not aware of other sighna and symptoms about pregnancy and birth complication. It might be related with why level of childbirth fear is high in preterm premature rupture of membranes group. The fact that there is no pregnant women experiencing low level childbirth fear and the determination that the women applying to the emergency service only due to the delayed pregnancies experience medium level childbirth fear are the eyecatching findings of the study (Table 3 ). In addition to the stress caused by the pregnancy and childbirth, emergency services are the units that have rapid patient traffic and that may be the intensive stress resource in terms of the patient. $^{18-23}$ 
In the study; it has been found out that women experience higher levels of childbirth fear in the desired, but unplanned pregnancies (Table 5). If the pregnancy has occurred in an unplanned way, a part of the mother candidates have hardships in the acceptance of the process of pregnancy. ${ }^{24}$ It has been observed that women who are older and having unplanned pregnancy have childbirth fear in higher ratios. ${ }^{25}$ This situation shows similarities with the results of the study.

In the study, it has been determined that those not having any training of preparation for childbirth experience the childbirth fear in higher levels (Table 5). A study has been conducted with 109 healthy primigravid women for the purpose of determining the impact of the exercises and prenatal preparation trainings on controlling the childbirth fear and pain. It has been detected that the childbirth fear has significantly decreased in the women participating in the exercise program, but it has not decreased the childbirth fear in the women participating in the traditional childbirth courses. ${ }^{26}$ It has been found out that the psychoeducation conducted with 1410 women whose pregnancy is between the weeks 24-34 in Australia to decrease the childbirth fear is efficient in decreasing the childbirth fear level in the pregnant women and in increasing the childbirth self-confidence. ${ }^{12}$ In addition; it has also been determined that almost half of the pregnants participating in the classes of preparation for childbirth experience childbirth fear. ${ }^{27}$ It is a known fact that all the pregnants cannot benefit from the training centres in our country. Having a training before childbirth has been shown to be efficient in decreasing the fear levels due to the changing of the wrong knowledge existent related to taking a training before childbirth. ${ }^{11}$ It could be said that participation to childbirth preparation classes decreases the fear level of the women due to the fact that it ensures attainment of knowledge related to the pregnancy, childbirth and postnatal period. ${ }^{28}$

It has been determined that the childbirth fear level of those not feeling themselves ready for the birth during the childbirth is higher than those feeling themselves ready (Table 5). Giving correct and sufficient information to the pregnant women related to the pregnancy and childbirth via the video and visual representation techniques is one of the most effective non-pharmacological ways for the handling of fear. Having sufficient knowledge is considered as a factor facilitating the decision making in the issues related to health. ${ }^{15}$ The finding that the enlightenment of the women and the provision of readiness for childbirth are important factors in decreasing the childbirth fear and the negative impacts caused by the childbirth fear shows similarity with the literature. ${ }^{29}$

The fact that study has been conducted in a single unit, it has been conducted with nulliparous women and no comparison has been made between the daylight and night working hours take place in the limitations. Furthermore, the environment of obstetric emergency unit is not relaxing features for pregnant women with high risk. Additionally pregnant women are not educated and ready for childbirth emergency situations or complicated birth like normal childbirth process.

\section{Conclusion}

Pregnants should be informed and awareness should be raised in the issue of the danger symptoms possible to occur in pregnancy and the real birth symptoms. Classes for preparation for childbirth should be extended. The health personnel working in the emergency services should be informed in the issue of the childbirth fear and the impacts of application to hospital on the pregnant and family. It is necessary to form correct, efficient and applicable policies regarding the delivery and usage of the emergency health services of the country.

\section{References}

1. Alehagen S, Wijma K, Wijma B. Fear of childbirth before, during and after childbirth. Acta Obstetrica and Gynecologica. 2006;85:56-62. doi: $10.1080 / 00016340500334844$.

2. Demir LS. The situation in Maternal Mortals and Konya. T. C. The Ministry of Health Konya Public Health Directorate approaches maternal death prevention and emergency obstetric care. Symposium Book; 2013;1-5. (Original Work in Turkish).

3. Moyo NT, Liljestrand J. Emergency Obstetric Care: Impact on emerging issues. International Journal of Gynecology Obstetric. 2007;98:175-177. doi:10.1016/j.ijgo.2007.05.013.

4. Alderdice F, Lynn F. Factor structure of the prenatal distress questionnaire. Midwifery. 2011;27:553-539. doi: 10.1016/j.midw.2010.05.003

5. Ertuğrul $\mathrm{M}$, Okumuş $\mathrm{H}$, Aluş Tokat $\mathrm{M}$, et al. Psychometric evaluation of the Tilburg pregnancy distress scaleTurkish version (TPDS-T). J Transcultural Nursing. 2015;26:499-506. doi: 10.1177/1043659614531795.

6. Glazier R, Elgar F, Goel V, et al. Stress, social support and emotional distress in a community sample of pregnant women. Journal of Psychosomatic and Obstetric Gynecology. 2004;25:247-255. doi: 10.1080/01674820400024406.

7. Körükcü Ö, Kabukcuoğlu K. An effective method for skill 
development in obstetric emergencies: Simulationbased training. Journal of Research in Education and Teaching. 2016;5:38.(Original Work in Turkish).

8. Çınar O, Çevik E, Salman N, et al. Emergency severity index triage system and implementation experience in a university hospital. Türkiye Acil Tıp Dergisi. 2010;10:126-131.

9. Wijma K, Wijma B, Zar M. Psychometric aspects of the W-DEQ; A new questionnaire for the measurement of fear of childbirth. Journal of Psychosomatic Obstetrics and Gynecology. 1998;19:84-97. doi: 10.3109/01674829809048501.

10. Körükcü Ö, Kukulu K, Firat MZ. The reliability and validity of the Turkish version of the Wijma delivery expectancy/experience questionnaire (W-DEQ) with pregnant women. J Psychiatric and Mental Health Nursing. 2012;19:193-202. doi: 10.1111/j.13652850.2011.01694.x.

11. Serçekuş $P$, Mete $S$. Turkish women's perceptions of antenatal education. International Nursing Review. 2010;57:395-401. doi: 10.1111/j.14667657.2009.00799.x.

12. Toohill J, Fenwick J, Gamble J, et al. Prevalence of childbirth fear in an Australian sample of pregnant women. BMC Pregnancy and Childbirth. 2014;14-275. doi: 10.1186/1471-2393-14-275. doi: 10.1186/14712393-14-275.

13. Alehagen S, Wijma K, Wijma B. Fearduringlabor Acta Obstetricia et Gynecologica Scandinavica. 2001;80:315320. doi: 10.1034/j.16000412.2001.080004315.x.

14. Toohill J, Fenwick J, Gamble J, et al. Randomized controlled trial of a psycho education intervention by midwives in reducing childbirth fear in pregnant women. Birth. 2014;41:384-394. doi: 10.1111/birt.12136.

15. Khedr NFH, Eldeen MS. Effect of healthy instructions on reducing pregnant women's fear of normal delivery and preferences for cesarean delivery. American Journal of Nursing Science. 2017;6:176-184. doi: 10.11648/j.ajns.20170603.15.

16. Gao LL, Liu XJ, Fu BL, et al. Predictors of childbirth fear among pregnant Chinese women: A cross-sectional questionnaire survey. Midwifery. 2015;31:865-870. doi: 10.1016/j.midw.2015.05.003.

17. Doğru HY, Oktay G, Özsoy $A Z$, et al. The evaluation of pregnants admitted to emergency unit: Tertiary single centre experience. Van Medical Journal. 2017;24(3):157-162. doi: 10.5505/vtd.2017.68442.(Original Work in Turkish).

18. Størksen HT, Garthus-Niegel S, Vangen S, et al. The impact of previous birth experiences on maternal fear of childbirth. Acta Obstetricia et Gynecologica
Scandinavica.

2013;92:318-324.

doi:

10.1111/aogs.12072.

19. Serçekuş P. Intervention for fear of childbirth: Hypnobirthing. TAF Preventive Medicine Bulletin. 2011;10:239-242. doi: 10.5455/pmb.20101123011947. (Original Wok in Turkish).

20. Fenwick J, Toohill J, Creedy DK, et al. Sources, responses and moderators of childbirth fear in Australian women: A qualitative investigation. Midwifery. 2015;31:239-246. doi: 10.1016/j.midw.2014.09.003.

21. Larsson B, Karlström A, Rubertsson C, et al. The effects of counselling on fear of childbirth. Acta Obstetricia et Gynecologica Scandinavica. 2015;94:629-636. doi: 10.1111/aogs.12634.

22. Ryding EL, Lukasse M, Parys ASV, et al. Fear of childbirth and risk of cesarean delivery: A cohort study in six European countries. Birth. 2015;42:48-55. doi: 10.1111/birt.12147.

23. Størksen HT, Garthus-Niegel S, Adams SS, et al. Fear of childbirth and elective caesarean section: A populationbased study. BMC Pregnancy and Childbirth. 2015;15:221-230. doi: 10.1186/s12884-015-0655-4.

24. Subaşı B, Özcan H, Pekçetin S, et al. Effects of delivery education on childbirth anxiety and fear. Selçuk Tıp Dergisi. 2013;29:165-167. (Original Work in Turkish).

25. Aksoy AN, Ozkan H, Gundogdu G. Fear of childbirth in women with normal pregnancy evolution. Clinical Experimental Obstetrics and Gynecology. 2015;42:17983.

26. Guszkowska M. The effect of exercise and childbirth classes on fear of childbirth and locus of labor pain control. Anxiety, Stress \& Coping. 2014;27:176-189. doi: 10.1080/10615806.2013.830107.

27. Melender HL. Fears and coping strategies associated with pregnancy and childbirth in Finland. Journal of Midwifery and Women's Health. 2008;47:256-263. doi: 10.1016/S1526-9523(02)00263-5.

28. Dönmez S, Yeniel ÖA, Kavlak O. Vajinal doğum ve sezaryen doğum yapan gebelerin durumluk kaygı düzeylerinin karşılaştırılması. Comparison of the stait anxiety levels of pregnants women who have vaginal or cesarean delivery. Gümüşhane Üniversitesi Sağlık Bilimleri Dergisi. 2014;3(3):908-920. (Original Work in Turkish).

29. El-Aziz SNA, Mansour SE, Hassan NF. Factors associated with fear of childbirth: It's effect on women's preference for elective cesarean section. Journal of Nursing Education and Practice. 2017;7:133-145. doi.org/10.5430/jnep.v7n1p133 


\section{PEER REVIEW}

Not commissioned. Externally peer reviewed.

\section{CONFLICTS OF INTEREST}

The authors declare that they have no competing interests.

\section{FUNDING}

The study has been funded by the Akdeniz University Research Council.

\section{ETHICS COMMITTEE APPROVAL}

Ethical approval was taken from Akdeniz University Clinical Trials Ethics Committee (approval reference number: 236). 
Table 1: Definitive properties of the participants $(n=473)$

\begin{tabular}{|c|c|c|}
\hline Properties & Number & $\%$ \\
\hline \multicolumn{3}{|l|}{ Age (years) } \\
\hline 20 and below & 119 & 25.1 \\
\hline $21-25$ & 229 & 48.4 \\
\hline $26-30$ & 86 & 18.2 \\
\hline $31-35$ & 31 & 6.6 \\
\hline $36-41$ & 8 & 1.7 \\
\hline \multicolumn{3}{|l|}{ Education } \\
\hline Literate & 29 & 6.1 \\
\hline Primary School & 74 & 15.6 \\
\hline Middle School & 170 & 35.9 \\
\hline High School & 134 & 28.4 \\
\hline University & 66 & 14.0 \\
\hline \multicolumn{3}{|c|}{ Working in a regular job } \\
\hline No & 417 & 88.2 \\
\hline Yes & 56 & 11.8 \\
\hline \multicolumn{3}{|l|}{ Week of Pregnancy } \\
\hline Week 29-32 & 24 & 5.0 \\
\hline Week 33-36 & 104 & 22.0 \\
\hline Week 37-40 & 296 & 62.6 \\
\hline Week 41 and above & 49 & 10.4 \\
\hline \multicolumn{3}{|l|}{ Plan of pregnancy } \\
\hline Desired, unplanned & 173 & 36.6 \\
\hline Desired, planned & 300 & 63.4 \\
\hline \multicolumn{3}{|c|}{ Training of birth preparation } \\
\hline No & 444 & 93.9 \\
\hline Yes & 29 & 6.1 \\
\hline \multicolumn{3}{|c|}{ Knowledge of Childbirth } \\
\hline Yes & 38 & 8.0 \\
\hline No & 435 & 92.0 \\
\hline \multicolumn{3}{|c|}{ Readiness for Childbirth } \\
\hline Yes & 237 & 50.1 \\
\hline No & 236 & 49.9 \\
\hline
\end{tabular}

Table 2: Childbirth fear levels of the women applying to emergency service according to "Wijma Childbirth Expectation/Experience - Version A"

\begin{tabular}{|l|l|l|}
\hline Childbirth Fear Levels & Number & $\%$ \\
\hline Low Level (0-37) & 58 & 12.3 \\
Medium Level (38-65) & 165 & 34.8 \\
High Level (66-84) & 147 & 31.1 \\
Clinical Level (85-165) & 103 & 21.8 \\
Mean average: :66.33 \pm 25.25 & 473 & 100 \\
Total & & \\
\hline
\end{tabular}


Table 3: Relation between the reasons for applying to emergency and childbirth fear $(n=473)$

\begin{tabular}{|l|l|l|l|l|l|}
\hline \multirow{2}{*}{ Application Reason } & \multirow{2}{*}{$\mathbf{n}(\%)$} & \multicolumn{2}{|c|}{ Scale point } & \multirow{2}{*}{$\mathbf{F}$} & \multirow{2}{*}{$\mathbf{p}$} \\
\cline { 3 - 4 } & & $\overline{\mathbf{x}}$ & SD & & \\
\hline Pain & $320(67.7)$ & 66.00 & 24.26 & & \\
Early membrane rupture & $75(15.8)$ & 71.87 & 28.33 & & \\
Delayed pregnancies & $35(7.4)$ & 54.09 & 25.09 & \multirow{2}{*}{3.263} & \multirow{2}{*}{$0.012^{*}$} \\
Bleeding & $35(7.4)$ & 67.46 & 23.06 & & \\
Hypertension & $8(1.7)$ & 74.63 & 29.91 & & \\
Total & $473(100)$ & 66.33 & 25.25 & & \\
\hline
\end{tabular}

* $P<.05$

Table 4: Distribution of the groups forming the difference between the reasons for applying to emergency service and childbirth fear $(n=473)$

\begin{tabular}{|c|c|c|c|c|}
\hline \multirow{2}{*}{$\begin{array}{l}\text { Reason for Application to Emergency } \\
\text { Service }\end{array}$} & \multirow{2}{*}{$\begin{array}{l}\text { Other Reasons of Application to Emergency } \\
\text { Service }\end{array}$} & \multirow{2}{*}{$\mathbf{p}$} & \multicolumn{2}{|c|}{$\begin{array}{l}\text { 95\% Confidence } \\
\text { Interval }\end{array}$} \\
\hline & & & $\begin{array}{l}\text { Lower } \\
\text { limit }\end{array}$ & $\begin{array}{l}\text { Upper } \\
\text { limit }\end{array}$ \\
\hline \multirow{4}{*}{ Pain } & Early membrane rupture & 0.510 & 0.4774 & 0.1241 \\
\hline & Delayed pregnancies & 0.128 & 0.0552 & 0.7796 \\
\hline & Bleeding & 0.999 & 0.4604 & 0.3744 \\
\hline & Hypertension & 0.922 & 10.995 & 0.5790 \\
\hline \multirow{4}{*}{ Early membrane rupture } & Pain & 0.510 & 0.1241 & 0.4774 \\
\hline & Delayed pregnancies & $0.018^{*}$ & 0.0589 & $1.0188^{*}$ \\
\hline & Bleeding & 0.946 & 0.3463 & 0.6136 \\
\hline & Hypertension & 0.999 & 0.9556 & 0.7885 \\
\hline \multirow{4}{*}{ Delayed pregnancies } & Pain & 0.128 & 0.7796 & 0.0552 \\
\hline & Early membrane rupture & $0.018^{*}$ & 10.188 & $-0.0589^{*}$ \\
\hline & Bleeding & 0.289 & 0.9657 & 0.1553 \\
\hline & Hypertension & 0.357 & 15.412 & 0.2964 \\
\hline \multirow{4}{*}{ Bleeding } & Pain & 0.999 & 0.3744 & 0.4604 \\
\hline & Early membrane rupture & 0.946 & 0.6136 & 0.3463 \\
\hline & Delayed pregnancies & 0.289 & 0.1553 & 0.9657 \\
\hline & Hypertension & 0.970 & 11.360 & 0.7016 \\
\hline \multirow{4}{*}{ Hypertension } & Pain & 0.922 & 0.5790 & 10.995 \\
\hline & Early membrane rupture & 0.999 & 0.7885 & 0.9556 \\
\hline & Delayed pregnancies & 0.357 & 0.2964 & 15.412 \\
\hline & Bleeding & 0.970 & 0.7016 & 11.360 \\
\hline
\end{tabular}

$p<0.05$ 
Table 5: The relation between the childbirth fear and plan of pregnancy, knowledge about childbirth and readiness for childbirth $(n=473)$

\begin{tabular}{|c|c|c|c|c|c|c|c|c|}
\hline \multirow{2}{*}{ Plan of Pregnancy } & \multirow{2}{*}{ No } & \multicolumn{2}{|c|}{ Scale Point } & \multirow{2}{*}{ Difference } & \multirow{2}{*}{$t$} & \multirow{2}{*}{$p$} & \multicolumn{2}{|c|}{ Levene F test } \\
\hline & & $\overline{\mathbf{x}}$ & SD & & & & $\mathbf{F}$ & $\mathbf{p}$ \\
\hline \multicolumn{9}{|l|}{ Plan of Pregnancy } \\
\hline Desired but unplanned & 173 & 74.46 & 22.46 & & & & 4.263 & 0.04 \\
\hline Desired and planned & 300 & 61.64 & 25.63 & 0.39 & 5.673 & 0.000 & & \\
\hline \multicolumn{9}{|c|}{ Knowledge about childbirth } \\
\hline Yes & 38 & 51.79 & 29.82 & 0.13 & -3.751 & 0.000 & 4.888 & 0.028 \\
\hline No & 435 & 67.60 & 24.45 & & & & & \\
\hline \multicolumn{9}{|l|}{ Readiness for childbirth } \\
\hline Yes & 237 & 58.01 & 24.09 & & & & & \\
\hline No & 236 & 74.68 & 23.64 & -0.51 & -7.594 & 0.000 & 1.343 & 0.247 \\
\hline
\end{tabular}

$p<0.05$ 